\title{
Research of the power plant operational states with block structure
}

\author{
Nina Kosmynina ${ }^{1, *}$, and Victor Yarmonov ${ }^{1}$ \\ ${ }^{1}$ National Research Tomsk Polytechnic University, 634050 Tomsk, Russia
}

\begin{abstract}
In this article the research technique block structure power plant operational states is offered. As an example the operating power plant of OOO Siberian Generation Company with block structure of turbogenerators connection is considered. The choice of the operating power plant has allowed to receive to carry out the analysis real long and emergency states. The offered technique of states identification and the analysis can be used for power plant of other structure after the corresponding correction.
\end{abstract}

\section{Introduction}

The main feature of block structure power plants is connection of generators to switchgear by means power transformers or autotransformers. Such schemes are used for nuclear, powerful hydroelectric power plants and thermal power stations. In case of nuclear and thermal power stations generators have the drive from the steam turbine - turbogenerators are used; for hydroelectric power plants - hydrogenerators with the drive of the electric generator from the hydraulic turbine are used. The difference in generators doesn't influence structure and the modes of power plant. In this article the thermal power plant working as a part of Ltd company "The Siberian generation company" is considered. Feature of power plants block diagrams is power development from generators to power transformers and to voltage switchgear [1]. In the figure 1 the block diagram of the studied power plant is shown. The studied power plant has three open voltage switchgear: high voltage switchgear (HV switchgear), the middle voltage switchgear -1 (MV-1 switchgear) and the middle voltage switchgear -2 (MV-2 switchgear). Switchgears have the following classes of voltage: HV switchgear - $500 \mathrm{kV}, \mathrm{MV}-1$ switchgear $-220 \mathrm{kV}$ and MV-2 switchgear $-110 \mathrm{kV}$. At the station seven turbogenerators are used: six turbogenerators (G1, G2, G3, G4, G5, G6 with type TVF-165-2У3, and one turbogenerator (G7 ) with type TGB-500-2. Turbogenerators TVF $-165-2 \mathrm{y} 3$ the Russian manufacturer with power 165 MW have direct hydrogen cooling of rotor winding and hydrogen indirect cooling of stator winding [2]. The turbogenerator excitement system is static thyristor, according to the scheme of self-excitation. Turbogenerators TGV -500-2 the Kharkiv manufacturer with power $500 \mathrm{MW}$ have direct hydrogen cooling of stator winding and water direct cooling of rotor winding [2]. The turbogenerator excitement system is static thyristor STVB-12B.

\footnotetext{
* Corresponding author: kosm_nm@tpu.ru
} 


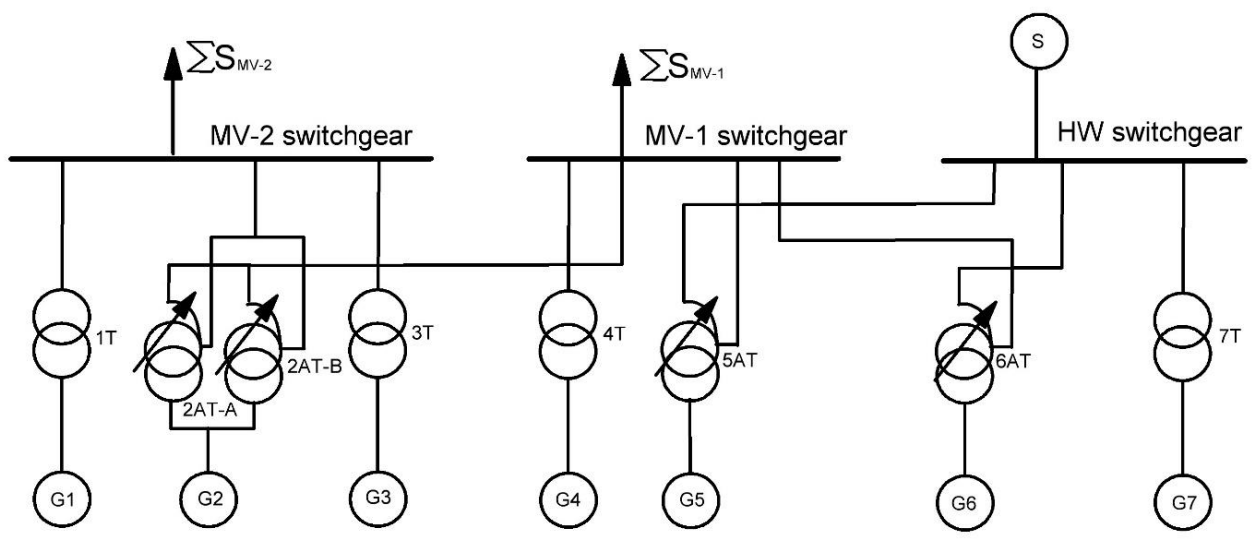

Fig. 1. The block diagram of the studied power plant.

Turbogenerators TVF-165-2У3 the Russian manufacturer with power $165 \mathrm{MW}$ have direct hydrogen cooling of rotor winding and hydrogen indirect cooling of stator winding . [2]. The turbogenerator excitement system is static thyristor, according to the scheme of self-excitation. Turbogenerators type TGB $-500-2$ the Kharkiv manufacturer with power $500 \mathrm{MW}$ have direct hydrogen cooling of stator winding and water direct cooling of rotor winding [2]. The turbogenerator excitement system is static thyristor, STVB-12B. All turbogenerators work according to the scheme of blocks: the generator - the two winding transformer [1] (G1-1T, G3-3T, G4-4T, G7-7T) with the generating switch; generator autotransformer (G5-5AT, G6-6AT, G2-2AT-A,2AT-B). Types of block transformers are TDSN-200000/110, TDS -200000/220, 3xORTS -210000/500 [2]; types of block autotransformers are ATDSTN -250000/220/110, ATDSTN -500000/500/220. Power of the ТДЦ-200000/110 is $200 \mathrm{MB}^{*} \mathrm{~A}$ with higher voltage $110 \mathrm{kV}$. Power of the TDS $200000 / 220$ is $200 \mathrm{MB}^{*} \mathrm{~A}$ with higher voltage $220 \mathrm{kV}$. Power of the $3 \mathrm{xORDS}-210000 / 500$ is $630 \mathrm{MB}^{*} \mathrm{~A}$ with higher voltage $500 \mathrm{kV}$. Cooling system: compulsory circulation of oil and air, with not directed oil stream. Power of the ATDSTN $-250000 / 220 / 110$ is 250 MB*A, and ATDSTN -500000/500/220 has $500 \mathrm{MB} * \mathrm{~A}$. Autotransformer voltage tap of ATDSTN -250000/220/110 are 220 кB - higher voltage , 110 кB - middle voltage. Autotransformer voltage tap of ATDSTN -500000/500/220 are $500 \mathrm{kV}$ higher voltage , 220 $\mathrm{kV}$ middle voltage [4]. Cooling system: compulsory circulation of oil and air, with not directed oil stream. The autotransformers has the built-in device RPN for an opportunity to carry out adjustment of voltage under loading without shutdown of the autotransformer. All autotransformers carry out the connection between switchgears of power plant. The power supply system (in drawing it is designated as source $S$ ) has connection with station on the HV switchgear. The MV -1 switchgear has middle voltage -1 external consumers loading of the total

power

of

SMV-1. The MV -2 switchgear has middle voltage - 2 external consumers loading of the total power of SMV-2.

\section{Operational states classification}

Depending on external consumer loading, an operational condition of block diagram elements the following operational states of power plant are possible: normal, repair, postemergency. The normal state is characterized by regime parameters admissible values : voltages, currents, capacities. At the same time distinguish the states of the maximum and minimal load of external consumers. For the studied power plant the possible load states 
described above exist both for MV -1 switchgear and for MV -2 switchgear. The scheme represented in the figure 1 corresponds to these long states.

There are repair states at the scheduled preventive and capital connection transformers repairs. For the studied power plant are possible two repair states. The first state is available at shutdown of one connection autotransformer MV-1 switchgear - MV-2 switchgear. The second state is available at shutdown of one connection autotransformer of MV-2 switchgear - HV switchgear. All possible operational states are considered: change of loading (min., max.) on MV-1 switchgear and MV-2 switchgear.

Only one of postemergency states is considered: shutdown of one block from MV-1 switchgear or from MV-2 switchgear, as emergence two postemergency states is an improbable event. Only one of the repair states is considered: shutdown of connection autotransformers MV-1 switchgear - MV-2 switchgear or MV-2 switchgear - HV switchgear as existence two repair the mode is an improbable event.

\section{Operational states analysis}

All electrical equipment has work qualitatively in all operational states. Therefore the greatest values of currents or powers flowing through the power plant electrical equipment must be taken into account. The currents and power values in the operational states is carried out on the basis of power balance $\mathrm{f}$ or power plant nodes-terminal. So, terminals of each block generator (G1, ... G7); autotransformers neutral and each switchgear are nodes of the studied power plant. The direction and designations of power flows are presented in the figure 2 .

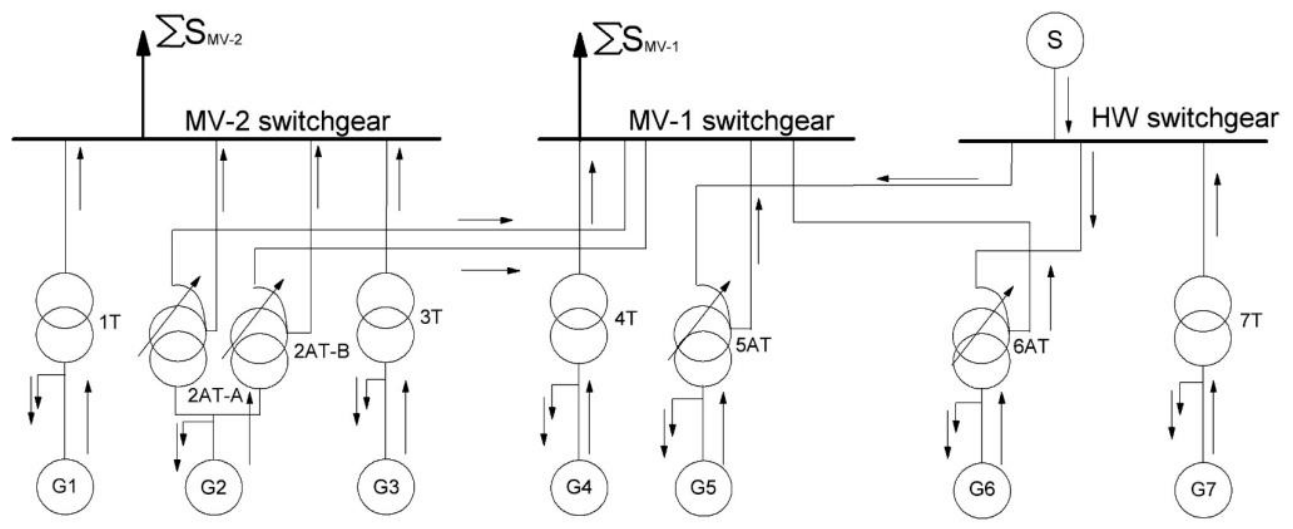

Fig. 2. The power flows block diagram plant.

Principles of the power overflows direction: from generators, to external loading; to common auxiliary (internal loading), from the two winding block transformer to switchgear; randomly for the middle and high terminal of the three winding autotransformer.

Below the example of power flows definition for the connection autotransformer 2AT-B is given. The power flow on the lowest voltage terminal 2AT-B is defined from the power balance equation of the G2 generator node. The power flow on the middle voltage terminal 2AT-B is defined from the power balance equation of the MV-1 switchgear node.

The power flow on the high voltage 2AT-B is defined from the power balance equation of autotransformer neutral. 
It should be noted that by deducing the balance equations within power plant losses of electric equipment elements power in aren't considered.

The example of one operational states calculation with using of the "RastrWin3" program without a common auxiliary power is presented in the figure 3 .

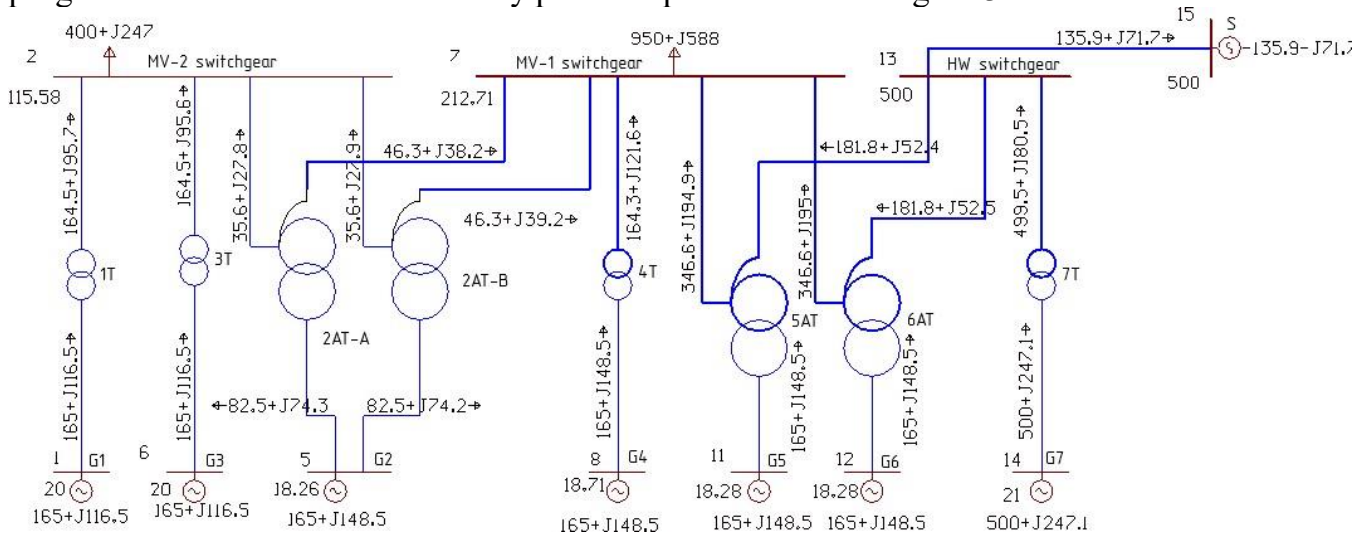

Fig. 3. The one operational states calculation in the "RastrWin3" program.

The RastrWin program complex is intended for the solution of tasks of calculation, the analysis and optimization of the electrical systems states. In Russia the main users of RastrWin are System Operator of the Unified Energy System (SO UES) and its branches.

The programs allowing to make a research of the different power plants operational states are developed for master preparation at the Tomsk Polytechnic University. The program is constructed by the linear principle: the data input windows of generators and loadings; the original structure window (it is presented in the figure 4), the window of the operational states choice, the results window [3].

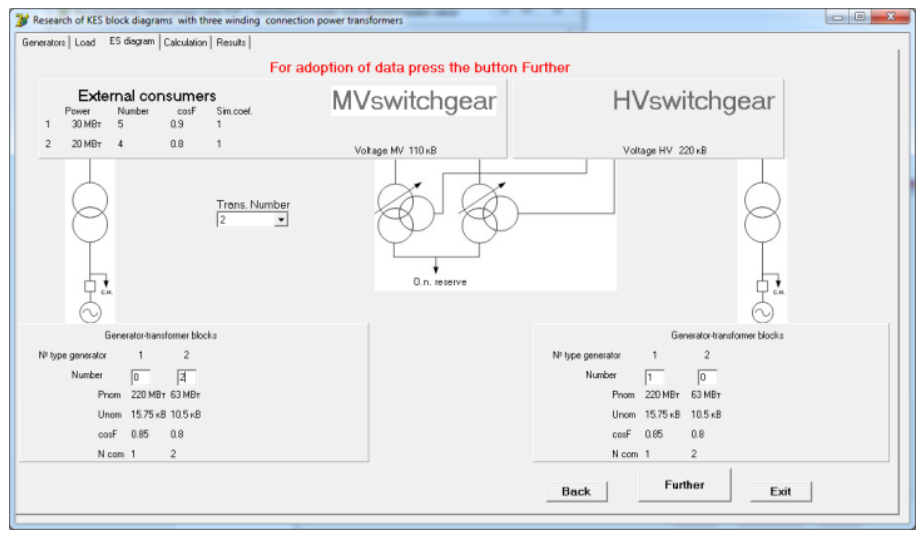

Fig. 4. Window of the power plant block diagram formation.

Power flows via transformers are a basis for determination of the required rated power of the equipment and its choice. In case of block two winding transformers the required rated power is equal to the block generator power. The required rated power for three winding the transformer $\mathrm{S}_{\mathrm{RATE}}=\max \left(\mathrm{S}_{\mathrm{LW}}, \mathrm{S}_{\mathrm{MV}}, \mathrm{S}_{\mathrm{HV}}\right), \mathrm{S}_{\mathrm{LW}}-$ power flow on a lower voltage winding; $S_{\mathrm{MV}}$ - power flow on a middle voltage winding; $\mathrm{S}_{\mathrm{HV}}$-power flow on a higher voltage winding. In case of the autotransformer $\mathrm{S}_{\mathrm{RATE}}>=\max \left(\mathrm{S}_{\mathrm{O}}, \mathrm{Ss}, \mathrm{S}_{\mathrm{LW}}\right) / \mathrm{Kco}$ ratio; $\mathrm{S}_{\mathrm{O}}$ - power flow on the common winding; $\mathrm{S}_{\mathrm{S}}$ - power flow on the series winding; $\mathrm{S}_{\mathrm{LW}}$ - power flow on the lower-voltage winding; Kco_ratio - co-ratio of an autotransformer coefficient 
is defined as Kco_ratio $=\left(\mathrm{U}_{\mathrm{HV}}-\mathrm{U}_{\mathrm{MV}}\right) / \mathrm{U}_{\mathrm{HV}}$. Besides, the selected autotransformer needs to be checked on loading of a lower-voltage winding: $\mathrm{S}_{\mathrm{LV}} \leq \mathrm{S}_{\mathrm{LV} \_}$rate.

The program for the autotransformer choice is also developed for students of the Tomsk Polytechnic University [4].

It is provided in the program: the entered data verification; the definition of an autotransformer operational states (the autotransformer, transformer, combined with power transfer to the middle voltage, combined with power transfer to the higher voltage); the calculation of the required autotransformer rated power.

\section{Conclusions}

In article the technique of operational states identification for power plant is developed: load, repair and postemergency.

For the operating block structure power plant the table of the possible operational states has been created.

The algorithm of power flows calculation via power transformers and autotransformers is offered.

The calculation protocol for one of the operational states is provided in the RastWin program.

The specialized program developed and used for operational states calculation at the Tomsk Polytechnic University is described.

Use of operational states calculations results for determination of the power transformers and autotransformers required rated is shown.

\section{References}

1. B.A. Starshinov, M.I.Piratorov, M.A.Kozinov, Electric part of power plants and substations ( MEI, Moscaw, 2015)

2. B.N. Neklepayev, I.P. Kryuchkov, Electric part of power plants and substations. Reference materials for course and degree design (Petersburg: BHV-St. Petersburg, 2014)

3. N. M. Kosmynina, T. T. Valiev. MATEC Web Conf. 91 (2017)

4. I. S. Tsoy, N. M. Kosmynina, IOP Conf. Series: Earth Environ. Sci. 27 (2015) 